\title{
Secure care: more harm than good
}

\author{
Andreas Pilarinos MPP, Perry Kendall MD, Danya Fast MA PhD, Kora DeBeck MPP PhD
}

Cite as: CMAJ 2018 October 15;190:E1219-20. doi: 10.1503/cmaj.180700

M

any who overdose on drugs in British Columbia are youth under the age of 19 years, ${ }^{1}$ and calls for "secure care" legislation have intensified. Secure care legislation would legitimize the detention and forced care of youth who are deemed to be at immediate risk of serious physical or psychological harm and is intended as a last-resort mechanism to protect youth who are engaged in high-risk substance use. In Canada, secure care legislation has been enacted in Alberta, Saskatchewan, Manitoba, Ontario, Quebec, New Brunswick and Nova Scotia. ${ }^{2}$ However, restricting the liberties of youth to protect them from overdose and other drug-associated harms is a flawed approach and may have unintended consequences.

Secure care models vary by province. In some jurisdictions, parents and guardians are permitted to request court-mandated treatment for the youth under their care, whereas other jurisdictions restrict mandatory treatment to youth in the criminal justice system. Treatment type and duration also vary by province, but stabilization and "detoxification" are the primary goals of all secure care programs in Canada. In BC, Bill M 202 - 2018: Safe Care Act dictates the process by which youth are apprehended, detained and discharged from safe care facilities, but offers no details on the types of treatment to be provided.

To advocates of secure care, the proposed legislation is viewed as a tool to help youth in crisis who are resisting engagement with health and social services. Youth who are addicted to drugs are believed to lack control over their actions, and parents and guardians often feel responsible to intervene but often do not have the tools to do this. The difficulties of navigating a largely nonexistent system of addiction care for youth mean that parents and caregivers are often unable to connect youth with evidence-based treatments. ${ }^{3}$ Therefore, it is understandable that many families and caregivers are demanding additional tools to intervene and protect youth from potentially deadly high-risk substance use.

Although secure care may prove effective for select youth with strong supports, the evidence for mandatory treatment is weak. A meta-analysis of research on juvenile drug courts in North America suggested that youth mandated into treatment showed no significant improvements in substance use during or after treatment. ${ }^{4}$ Evidence from adult populations provides further grounds to oppose secure care. In a systematic review of studies on court-mandated treatment, authors found that forced

\section{KEY POINTS}

- In response to the ongoing overdose crisis and its effect on young people, British Columbia has been considering following the lead of other provinces and implementing secure care legislation, which would permit the apprehension, detention and forced treatment of youth who are engaged in high-risk substance use.

- Existing evidence suggests that mandatory addiction treatment does not lead to significant improvements in substance use outcomes and can be destabilizing, increasing the risk of subsequent overdose.

- Coercive approaches to substance use risks undermining trust and our ability to connect youth who live with intergenerational, childhood or institutional trauma with the health and social services they need most.

- Investing in accessible, evidence-driven interventions and building meaningful connections with youth will serve to better protect their health and safety than the belief that legislation can be used to "fix" them.

treatment did not improve outcomes for substance use. Instead, findings showed higher levels of mental duress, homelessness, relapse and overdose among adults after discharge from mandated treatment. ${ }^{5}$

Although addiction treatment programs are effective for some, it is important to recognize that they can also be destabilizing and cause harm. For example, it is well documented that rapid withdrawal and abstinence-oriented treatments lower opioid tolerance and, given the high likelihood of posttreatment relapse, increase the risk of nonfatal overdose after treatment. ${ }^{6}$ Although extrapolating research from adult to youth populations must be done with caution, these findings suggest that forcing youth into abstinence-oriented treatments through secure care approaches may be expected to have unintended, even deadly, consequences.

Another concern with secure care is that it fails to acknowledge that the youth who use drugs may live with intergenerational, childhood or institutional trauma. In a Vancouver cohort of street-involved youth who use drugs, nearly $50 \%$ had encountered the child welfare system and over $35 \%$ had been involved with the criminal justice system. ${ }^{7,8}$ For these youth, trust in health and social services has often been severely 
compromised, and coercive approaches risk further undermining our ability to connect youth to the services they need most. This hampers efforts to promote health-seeking behaviours and prevent drug-related harms including fatal overdoses. Given the historical and ongoing effects of colonization, the use of a secure care approach with Indigenous youth raises further concern. The legacy of colonization has resulted in an overrepresentation of Indigenous youth within the child welfare and criminal justice systems, ${ }^{9}$ suggesting that Indigenous youth may be particularly vulnerable to secure care measures. The forced care of young Indigenous people who engage in substance use may represent a continuation of colonial policies and state repression of Indigenous Peoples.

Instead of resorting to coercive measures, providing coordinated addiction treatment services across a continuum of care would better combat the current overdose crisis and drugrelated harms. Other necessary measures include ensuring access to evidence-based interventions that address early determinants of health and span from prevention and education to harm reduction services, and from substitution treatment to residential programs. Furthermore, despite success among adults, there is often hesitation to offer certain harm reduction and addiction treatment modalities to youth. For example, substitution treatments, such as methadone and buprenorphine-naloxone, have been shown to reduce the consumption of street-sourced opioids, improve uptake of other treatment interventions and reduce rates of overdose among youth but are often withheld from youth for fear that they encourage substance use and dependence. ${ }^{6,10}$ Needle exchange and supervised drug consumption programs are other evidence-based interventions that are less frequently offered to youth despite known benefits in reducing serious drug-related harms. ${ }^{10}$ Measures to improve utilization of these types of evidence-based interventions by youth will provide more opportunities to protect the health and well-being of youth who use drugs.

Although the allure of secure care is understandable, we must acknowledge the gaps within the existing care system for youth addiction and the potential for severe unintended consequences that may result from coercing youth into addiction treatment and care. Until we restructure our institutions and make the necessary investments in early interventions so that all families and youth have the emotional, social and material supports needed to flourish, secure care should not proceed. In the short term, investing in accessible, evidence-driven interventions and building meaningful connections with youth will serve to protect their health and safety better than will the belief that legislated coercion can be used to "fix" them.

\section{References}

1. British Columbia Coroners Service. Illicit drug overdose deaths in BC, January 1, 2008 - February 28, 2018. Vancouver: Ministry of Public Safety \& Solicitor General; 2018.

2. Charles G. Secure care summary report (part one): secure care legislation. Vancouver: School of Social Work and Division of Adolescent Health and Medicine, Department of Pediatrics, Faculty of Medicine, University of British Columbia; 2016.

3. Hadland SE, Kerr T, Li K, et al. Access to drug and alcohol treatment among a cohort of street-involved youth. Drug Alcohol Depend 2009;101:1-7.

4. Tanner-Smith EE, Lipsey MW, Wilson DB. Juvenile drug court effects on recidivism and drug use: a systematic review and meta-analysis. J Exp Criminol 2016;12:477-513.

5. Klag S, O'Callaghan F, Creed P. The use of legal coercion in the treatment of substance abusers: an overview and critical analysis of thirty years of research. Subst Use Misuse 2005;40:1777-95.

6. Srivastava A, Kahan M, Nader M. Primary care management of opioid use disorders: Abstinence, methadone, or buprenorphine-naloxone? Can Fam Physician 2017;63:200-5.

7. Omura JD, Wood E, Nguyen P, et al. Incarceration among street-involved youth in a Canadian study: implications for health and policy interventions. Int J Drug Policy 2014;25:291-6.

8. Barker B, Kerr T, Alfred GT, et al. High prevalence of exposure to the child welfare system among street-involved youth in a Canadian setting: implications for policy and practice. BMC Public Health 2014;14:197.

9. Aboriginal Children. Canada must do better: today and tomorrow. Canadian Council of Provincial Child and Youth Advocates; 2011.

10. A review of youth substance use services in B.C. Victoria (BC): British Columbia Representative for Children and Youth; 2016:89.

\section{Competing interests: None declared.}

This article has been peer reviewed.

Affiliations: British Columbia Centre on Substance Use (Pilarinos, Fast, DeBeck), Vancouver, BC; Interdisciplinary Studies Graduate Program (Pilarinos); School of Population and Public Health (Kendall), The University of British Columbia, Vancouver, BC; School of Public Policy (DeBeck), Simon Fraser University, Vancouver, BC

Contributors: Andreas Pilarinos and Kora DeBeck prepared the first draft of the manuscript. All of the authors made substantial intellectual contributions to the content of the manuscript and revised it critically, gave final approval of the version to be published and agreed to be accountable for all aspects of the work.

Correspondence to: Kora DeBeck, bccsu-kd@bccsu.ubc.ca 